Eur. J. Clin. Chem. Clin. Biochem.

Vol. 31, 1993, pp. 715-724

(C) 1993 Walter de Gruyter \& Co.

Berlin · New York

\title{
The Mass Concentrations of Serum Troponin T and Creatine Kinase-MB are Elevated before Creatine Kinase and Creatine Kinase-MB Activities in Acute Myocardial Infarction
}

\author{
By A. J. Bakker ${ }^{1}$, J. P. M. C. Gorgels ${ }^{3}$, B. van Vlies ${ }^{4}$, F. D. M. Haagen ${ }^{2}$ and Rina Smits ${ }^{1}$ \\ 1 Department of Clinical Chemistry, Stichting Klinisch Chemisch Laboratorium, Leeuwarden, The Netherlands \\ ${ }^{2}$ Department of Cardiology, Medisch Centrum Leeuwarden, Leeuwarden, The Netherlands \\ ${ }^{3}$ Department of Clinical Chemistry, Academisch Medisch Centrum, Amsterdam, The Netherlands \\ ${ }^{4}$ Department of Cardiology, Academisch Medisch Centrum, Amsterdam, The Netherlands
}

(Received May 3/August 18, 1993)

Summary: The time-related frequency of elevated results for the mass concentrations of the MB isoenzyme of creatine kinase and of troponin $\mathrm{T}$ were compared with that of creatine kinase and creatine kinase-MB activity in patients with acute myocardial infarction. Patients $(322 ; 175$ with and 147 without myocardial infarction) consecutively admitted for evaluation of possible acute myocardial infarction were investigated. Reference limits for troponin $\mathrm{T}(0.1 \mu \mathrm{g} / \mathrm{l})$ and creatine kinase-MB mass concentration $(5.0 \mu \mathrm{g} / \mathrm{l})$ were exceeded frequently in patients with unstable angina pectoris (troponin T $43 \%$, creatine kinase-MB mass concentration $24 \%$ ) in contrast to patients with no acute ischaemic heart disease (both $<5 \%$ ). Within 4 and between $4-8$ hours after onset of chest pain, the frequency of elevated results for creatine kinase-MB mass concentration and troponin $\mathrm{T}$ in patients with acute myocardial infarction was considerably higher $(20-30 \%)$ than for creatine kinase and creatine kinase-MB activity. Creatine kinase-MB mass concentration and troponin $\mathrm{T}$ both allowed earlier diagnosis of acute myocardial infarction than creatine kinase and creatine kinase-MB activity, but troponin $\mathrm{T}$ was not elevated before the creatine kinase-MB mass concentration.

\section{Introduction}

Early diagnosis of acute myocardial infarction is important for

(1) instigating and monitoring proper'therapy,

(2) preventing inappropriate usage of expensive coronary care beds, and

(3) avoiding premature hospital discharge of patients with myocardial infarction.

Diagnosis of acute myocardial infarction is based on the characteristic clinical history of anginal chest discomfort more than 30 minutes in duration, the evolution of typical electrocardiographic changes and the rise and fall of the activities of specific cardiac enzymes in blood. The positive predictive value of elec- trocardiographic abnormalities at admission has been reported to be $72 \%$ (1). Serial electrocardiograms, which are time-consuming, improved the positive predictive value, but nevertheless the electrocardiogram was misleading in about $8 \%$ of all acute myocardiat infarctions and indeterminate in an additional $12 \%$ (2). Therefore, measurement of specific cardiac enzymes and proteins play an important role in the early and definitive diagnosis of acute myocardial infarction in a significant number of patients.

\footnotetext{
1) Enzymes:

Alanine aminotransferase, EC 2.6.1.2,

Aspartate aminotransferase, EC 2.6.1.1,

Creatine kinase, EC 2.7.3.2,

Lactate dehydrogenase, EC 1.1.1.27
} 
Among the various biochemical approaches, determination of the enzyme activity of creatine kinase ${ }^{1}$ ) and creatine kinase isoenzyme $\mathrm{MB}$ are generally used for early diagnosis of acute myocardial infarction, although the resulting diagnosis is not unequivocal (3). The immunological determination of the mass concentration of creatine kinase-MB represents a recent advance towards greater specificity $(4-8)$; unlike the determination of the activities of creatine kinase and its MB-isoenzyme, it is not prone to interference from haemolysis $(9,10)$ or atypical and macromolecular forms of creatine kinase $(11-13)$. The immunological determination of the cardiospecific troponin T, a $M_{\mathrm{r}} 37000$ polypeptide subunit of the cardiac myofibrillar regulatory troponin complex, was also recently proposed as a very sensitive and specific marker for myocardial damage (14-18). It was suggested (15) that the release from the damaged myocardium led to a rise of troponin $\mathrm{T}$ in the serum, which preceded the rise of creatine kinase and creatine kinase-MB and remained elevated after myocardial infarction for up to several weeks (18), in contrast to the few days duration for the elevation of creatine kinase and creatine kinase-MB. Troponin $\mathrm{T}$ therefore seemed to be an attractive marker both for the early and the late diagnosis of myocardial infarction.

In the present evaluation, we validated the reference ranges for the assays under consideration, using results from patients admitted for evaluation of possible myocardial infarction, but shown to be free from this condition at the time. Furthermore, we studied the time-related frequency of elevated results for the mass concentration of creatine kinase-MB and troponin $\mathrm{T}$ and compared it with that of the activity of creatine kinase and creatine kinase-MB in patients with acute myocardial infarction.

\section{Materials and Methods}

Clinical studies

\section{Patients}

The study population consisted of all consecutive patients admitted during a nine month period to the coronary care unit of the "Medisch Centrum Leeuwarden" hospital in Leeuwarden, for evaluation of suspected myocardial infarction. Only those patients were included for whom the time of onset of chest pain was established with certainty and the time-period between onset of chest pain and admission was $<12$ hours. The final diagnosis, according to the criteria of the World Health Organization (19), was established by an independent cardiologist (B.v. V.), without knowledge of the results of the mass concentration of creatine kinase-MB and troponin $T$. Patients considered to have muscle injury (cases of resuscitation and/or defibrillation) were grouped separately, because muscle trauma possibly could influence the release pattern of the cardiac markers. On the other hand, patients who collapsed before admission were included in the study although muscle injury could not be excluded with certainty.

\section{Patients' samples}

Blood samples were taken at the time of admission to hospital and during the first 24 hours in a fixed time schedule at 07.30, 14.30 and 21.30 , which is routine in our hospital. The activities of creatine kinase, lactate dehydrogenase'), aspartate aminotransferase ${ }^{1}$ ) and alanine aminotransferase ${ }^{1}$ ) were determined as soon as possible, using the methods proposed by the International Federation of Clinical Chemistry, and creatine kinase-MB was assayed with an immunoinhibition method (reagents from Boehringer Mannheim, Mannheim, Germany). For the immunological determination of serum troponin $T$ and the mass concentration of creatine kinase-MB, samples were frozen at $-20^{\circ} \mathrm{C}$ until analysis.

Reference population for creatine kinase-MB mass concentration and troponin $T$

Reference ranges were established using sera from apparently healthy blood donors: 77 men and 45 women for the reference range for the mass concentration of creatine kinase-MB; 63 men and 32 women for the concentration of troponin $T$. These reference ranges were verified using the sera from patients admitted for evaluation of acute myocardial infarction, but shown to be free from this condition.

\section{Diagnostic criteria}

\section{Classification of the patients}

Patients were classified as acute myocardial infarction, unstable angina pectoris, without acute ischaemic heart disease, and as other cardiac diseases. The final diagnosis of myocardial infarction was established if a patient had at least two of the three following classic findings.

1) A clinical history of ischaemic chest discomfort of $>30 \mathrm{~min}$ duration.

2) Typical changes in at least 2 leads to the electrocardiographic recordings. If $Q$ waves $>0.04 \mathrm{~s}$ appeared, or an $\mathrm{R}$ wave increment gave an $R / S$ ratio $>1$ in leads $V 1$ and $V 2$, it was called $Q$ wave infarction. If ST segment depression $>1 \mathrm{~mm}$ occurred $0.08 \mathrm{~s}$ after the $\mathrm{J}$ point, or ST segment elevation $>1 \mathrm{~mm}$ persisted for at least 24 hours, it was called non-Q wave infarction.

3) Time-dependent changes of serum creatine kinase and creatine kinase-MB activity, with an initial rise (with a peak creatine kinase-MB activity exceeding twice the upper reference limit) and a subsequent fall.

Unstable angina pectoris was defined as typical anginal pain at rest in combination with reversible or persistent electrocardiographic changes, but without a peak value of the activity of creatine kinase-MB exceeding twice the upper reference limit.

Patients were classified as without acute ischaemic heart disease, if angina could be excluded by a definitive alternative source of the chest pain, or in cases of an atypical history with a negative stress electrocardiogram, myocardial scintigraphy or coronary angiography.

Patients with other heart diseases were grouped separately, together with a few patients for whom no final diagnosis could be made.

\section{Analytical methods}

Catalytic activity of creatine kinase was measured at $30^{\circ} \mathrm{C}$ with a Hitachi 717 analyser by the methad proposed by the International Federation of Clinical Chemistry (10), using commercial reagents (prod. Nos. 475742 and 475769) supplied by Boeh- 
ringer Mannheim. The upper reference limit for creatine kinase, based on blood donors, was $130 \mathrm{U} / \mathrm{l}$ for men and $90 \mathrm{U} / 1$ for women.

Cataly'tic activity' of creatine kinase- $M B$ was measured by immunoinhibition, using the appropriate antibody (Boehringer Mannheim; prod. No. 418234) and the creatinc kinase assay method, on the Hitachi 717 analyser. The upper reference limit for the activity of creatine kinase-MB, based on blood donors, was $15 \mathrm{U} / \mathrm{l}$.

Cardiac troponin $T$ in serum was measured with an enzymelinked immunosorbent assay (Boehringer Mannheim; prod. No. $1086987)$ developed by Katus et al. $(14,16)$. This assay was carried out in coated tubes, using the microprocessor-controlled batch analyser ES-33 (Boehringer Mannheim). The method is based on a single-step sandwich principle, with streptavidincoated test tubes as the solid phase and two monoclonal antihuman cardiac troponin $\mathrm{T}$ antibodies. The biotinylated antitroponin $\mathrm{T}$ antibody binds completely to the streptavidincoated test tube. This antibody binds troponin $T$ from standards or unknown samples. The peroxidase-labelled anti-troponin $\mathrm{T}$ antibody is captured by the complex of biotinylated anti-troponin $\mathrm{T}$ and troponin $\mathrm{T}$ bound to the streptavidin-coated test tube. The enzyme which remains in the test tubes after washing corresponds to the amount of troponin $T$ bound. This amount is quantified at $405 \mathrm{~nm}$ after substrate conversion [di-ammonium-2.2'-azino-bis(3-ethylbenzothiazoline-6-sulphonate)]. The sensitivity limit of this assay was established at $0.10 \mu \mathrm{g} / \mathrm{l}$ (mean absorbance of zero standard + 3 S. D.), which was in agreement with Katus et al. (16).

Mass concentration of creatine kinase- $M B$ was measured using the microparticle capture enzyme immunoassay (22) from Abbott Laboratories (Abbott Park, IL; prod. No. 2207-20). In the IMx creatine kinase-MB assay, a two-step protocol is used to quantify creatine kinase-MB. In the initial incubation, creatine kinase-MB in serum binds to anti-creatine kinase-MB microparticles. This microparticle/sample mixture is transferred to the glass fibre matrix of the IMx disposable container. Anticreatine kinase-MM alkaline phosphatase conjugate is added, followed by an additional incubation. The excess of conjugate is washed from the matrix and the substrate (4-methylumbelliferyl phosphate) is added. The amount of bound conjugate, which is proportional to the amount of creatine kinase-MB in the sample, is quantified from the rate at which the fluorescent product is formed. The sensitivity of this assay was reported to be $0.2 \mu \mathrm{g} / 1(20)$.

\section{Statistical analysis}

Differences in baseline characteristics (age, gender, clinical history and risk factors) between patients with and without acute myocardial infarction were determined using a $\chi^{2}$ or Fisher's

Tab. 1. Number of investigated patients and samples related to time and diagnosis.

\begin{tabular}{|c|c|c|c|c|}
\hline \multirow[t]{2}{*}{$\begin{array}{l}\text { Time since onset } \\
\text { of chest pain: }\end{array}$} & \multicolumn{2}{|c|}{$\begin{array}{l}\text { Number } \\
\text { of patients }\end{array}$} & \multicolumn{2}{|c|}{$\begin{array}{l}\text { Number } \\
\text { of samples }\end{array}$} \\
\hline & $<4 h$ & $<12 \mathrm{~h}$ & $<4 \mathrm{~h}$ & $<24 \mathrm{~b}$ \\
\hline \multicolumn{5}{|l|}{ Diagnosis } \\
\hline $\begin{array}{l}\text { Acute myocardial } \\
\text { infarction }\end{array}$ & 76 & 155 & 81 & 409 \\
\hline $\begin{array}{l}\text { Unstable angina pectoris } \\
\text { No acute ischaemic } \\
\text { heart disease }\end{array}$ & $\begin{array}{l}36 \\
27\end{array}$ & $\begin{array}{l}69 \\
58\end{array}$ & $\begin{array}{l}36 \\
29\end{array}$ & $\begin{array}{l}167 \\
127\end{array}$ \\
\hline $\begin{array}{l}\text { Other cardiac diseases } \\
\text { Muscle injury }\end{array}$ & $\begin{array}{r}9 \\
20\end{array}$ & $\begin{array}{l}15 \\
25\end{array}$ & $\begin{array}{r}9 \\
24\end{array}$ & $\begin{array}{l}38 \\
73\end{array}$ \\
\hline
\end{tabular}

exact test for categorial, and Student's t test for continuous variables. Comparison of the frequency of elevated results for the different markers within patient groups was also performed using Fisher's exact test.

For determining the clinical performance of the tested methods, we calculated sensitivity ( $\%$ of patients with myocardial infarction with a test result $>$ the upper reference limit) and specificity (\% of patients without myocardial infarction with a test result $\leq$ the upper reference limit). Receiver operating characteristic (ROC) curves were constructed to compare the discriminative power of the tests. Areas under the curve and differences between ROC curves were calculated according to the method proposed by Hanley et al. $(20,21)$.

\section{Results \\ Patient characteristics}

Our study encompassed 322 patients. Acute myocardial infarction was confirmed in 155 patients: 76 with $\mathrm{Q}$ wave infarction and 79 with non- $\mathrm{Q}$ wave infarction. Acute myocardial infarction was excluded in 127 patients: 69 were classified as unstable angina pectoris, 58 as lacking acute ischaemic heart disease (including 7 who collapsed before admission). Eleven patients had other cardiac diseases, and for 4 patients no definitive diagnosis could be made. Patients with other cardiac diseases and patients with no definitive diagnosis were classified together as one group. The same was done for patients $(n=25)$ who had been resuscitated and/or defibrillated; myocardial infarction was established in 20 of these, and other heart diseases were diagnosed in the remaining 5. Table 1 summarizes the number of patients in each patient group admitted within 4 and 12 hours after onset of chest pain, and the number of samples obtained within 4 and 24 hours after onset of chest pain, which were analysed for all four markers. Baseline characteristics (age, gender, risk factors and clinical history) of the patient groups (details not shown here) were not found to be significantly different between patients with and without myocardial infarction, with the exception of a history of angina pectoris. The mean age of the patient group without acute ischaemic heart disease was also significantly lower (about eight years) than for the other groups.

\section{Reference range for mass concentration of creatine kinase-MB}

The reference range for the mass concentration of creatine kinase-MB was estimated using 122 sera from apparently healthy blood donors. The upper reference limit (97.5th percentile) was determined according to the proposed guidelines of the International Federation of Clinical Chemistry (23) and was found to be $5.0 \mu \mathrm{g} / \mathrm{l}$. This reference limit was validated using all 


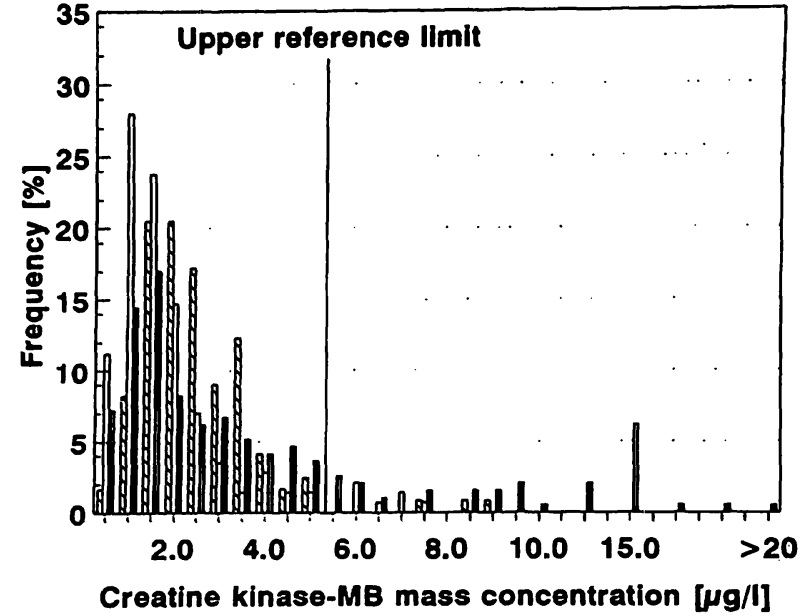

Fig. 1. Distribution of the mass concentration of creatine kinase-MB in 122 healthy blood donors $(\$), 58$ patients (127 samples) with no acute ischaemic heart disease ( $\square$ ) and 69 patients (167 samples) with a final diagnosis of unstable angina pectoris (a).

serum samples $(n=143)$ from the patients with no acute ischaemic heart disease. In this patient group $95 \%$ of the results were $\leq 5.0 \mu \mathrm{g} / \mathrm{l}$. Using all serum samples $(\mathrm{n}=194)$ from patients with a final diagnosis of unstable angina pectoris, however, only $77 \%$ of the results were $\leq 5.0 \mu \mathrm{g} / \mathrm{l}$. In this patient group $95 \%$ of the results were $<14 \mu \mathrm{g} / \mathrm{l}$. The distribution of the mass concentration of creatine kinase-MB in these three groups is shown in figure 1.

\section{Reference range for troponin $\mathrm{T}$}

The reference range for troponin $\mathrm{T}$ was estimated using 95 sera from healthy blood donors. All but 2 sera from this reference population had a troponin $T$ concentration below the sensitivity limit. Therefore, the upper reference limit for troponin $T$ was estimated at the sensitivity limit of $0.1 \mu \mathrm{g} / \mathrm{l}$. Again the upper reference limit was validated using all serum samples $(n=141)$ from the patients with no acute ischaemic heart disease. In this patient group $95 \%$ of the results were $\leq 0.1 \mu \mathrm{g} / \mathrm{l}$. Using all serum samples $(\mathrm{n}=204)$ from patients with a final diagnosis of unstable angina pectoris, however, only $60 \%$ of the results were $\leq 0.1$ $\mu \mathrm{g} / \mathrm{l}$. In this group $95 \%$ of the results were $<0.65$ $\mu \mathrm{g} / \mathrm{l}$. The distribution of the concentration of troponin $T$ in these three groups is shown in figure 2.

Frequency of elevated results in patient groups

The frequency of elevated results for the four cardiac markers was determined for all serum samples taken within 24 hours after onset of chest pain. Part of the patient group without acute myocardial infarction

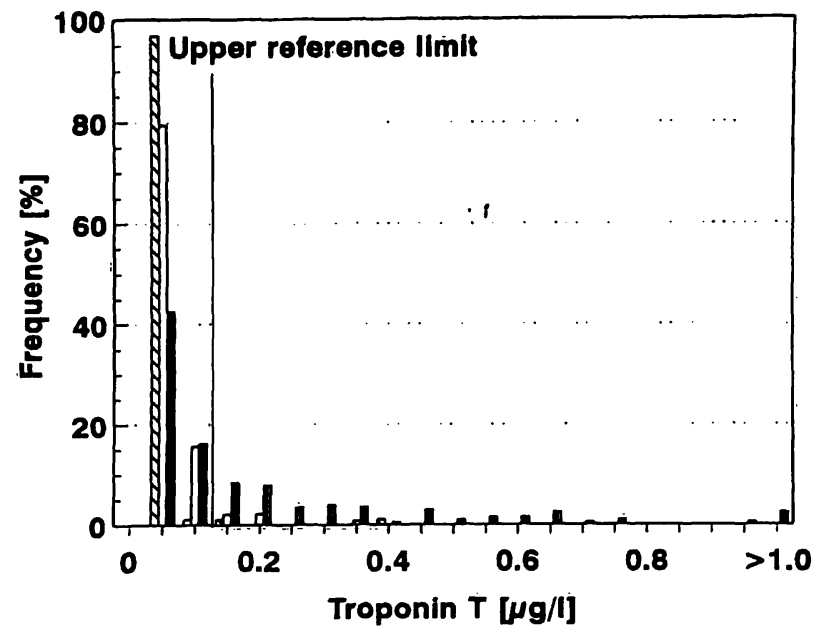

Fig. 2. Distribution of the concentration of troponin $\mathrm{T}$ in 95 healthy blood donors (\$), 58 patients (127 samples) with no acute ischaemic heart disease ( $\square$ ) and 69 patients (167 samples) with a final diagnosis of unstable angina pectoris (ii).

consisted of patients admitted with the presumptive diagnosis of acute myocardial infarction, but with a final diagnosis of no acute ischaemic heart disease. In this patient group, there were only minor differences between the frequencies of elevated results for all four markers (fig. 3). In patients with unstable angina pectoris, the frequency of elevated results for the activity of creatine kinase and creatine kinase-MB did not differ from that in patients with no acute is-

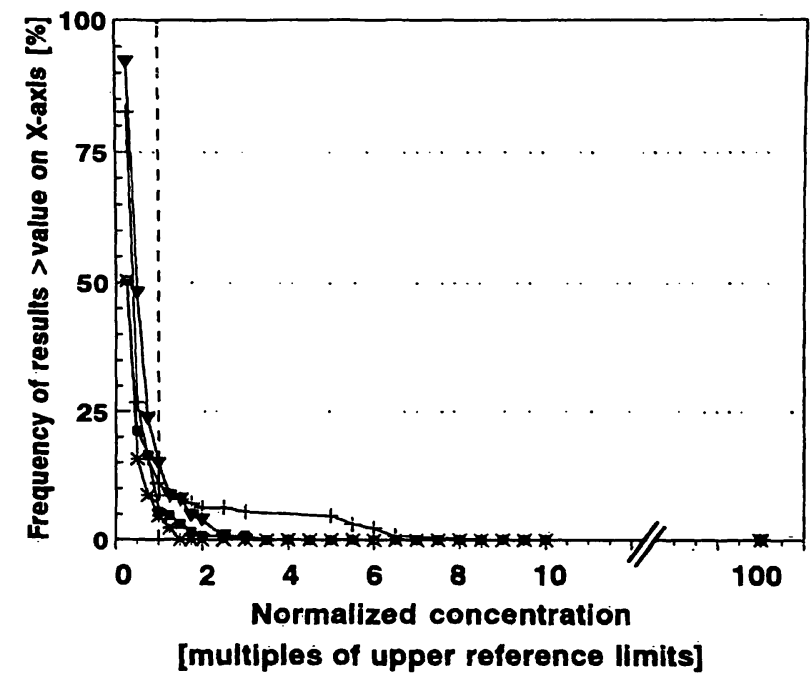

Fig. 3. Frequency $(\mathrm{Y})$ of results $>$ the normalized concentration value on the $\mathrm{X}$-axis $(\mathrm{X})$ for the activity of creatine kinase $(-\nabla-\nabla-)$ and its $M B$ isoenzyme $(-+-+-)$ and creatine kinase-MB mass concentration (-*-*-) and troponin $\mathrm{T}(-\square-\mathbf{-})$ ) in patients with no acute ischaemic heart disease (127 samples from 58 patients). Concentrations of the four markers on the $\mathrm{X}$-axis are given as multiples of the upper reference limits. The used upper reference limits were: creatine kinase: men $130 \mathrm{U} / \mathrm{i} ;$; women $90 \mathrm{U} / \mathrm{h}$, creatine kinase-MB activity: $15 \mathrm{U} / \mathrm{l}$, creatine kinase-MB mass concentration: $5.0 \mu \mathrm{g} / \mathrm{l}$, and troponin $\mathrm{T}: 0.1 \mu \mathrm{g} / \mathrm{l}$. 
chaemic heart disease. However, the frequency of elevated results for the mass concentration of creatine kinase-MB and troponin $\mathrm{T}$ was considerably higher in these patients (fig. 4). In patients with acute myocardial infarction, the frequency of elevated results for the four markers was related to the time interval between onset of chest pain and the timing of the sampling (figs. $5^{\mathrm{a}}-5^{\mathrm{d}}$ ). An overview of the frequency of elevated results in all patient groups is shown in table 2. For creatine kinase-MB mass concentration and troponin $\mathrm{T}$, table 2 lists both the frequency of elevated results using the upper reference limit, and the frequency of elevated results compared with the $95 \%$ limit determined from the data obtained in patients with unstable angina pectoris.

\section{Comparison of the diagnostic performance}

The diagnostic performances of the four markers were compared by ROC-curve analysis. As the release of the markers after myocardial infarction depends on the time elapsed since necrosis, we constructed timedependent ROC-curves (figs. $6^{\mathrm{a}}-6^{\mathrm{d}}$ ).

The four markers were also evaluated for their ability to detect patients with acute myocardial infarction within 12 or 24 hours after the onset of chest pain suggestive of acute myocardial infarction. Patients were considered to have a positive result for the

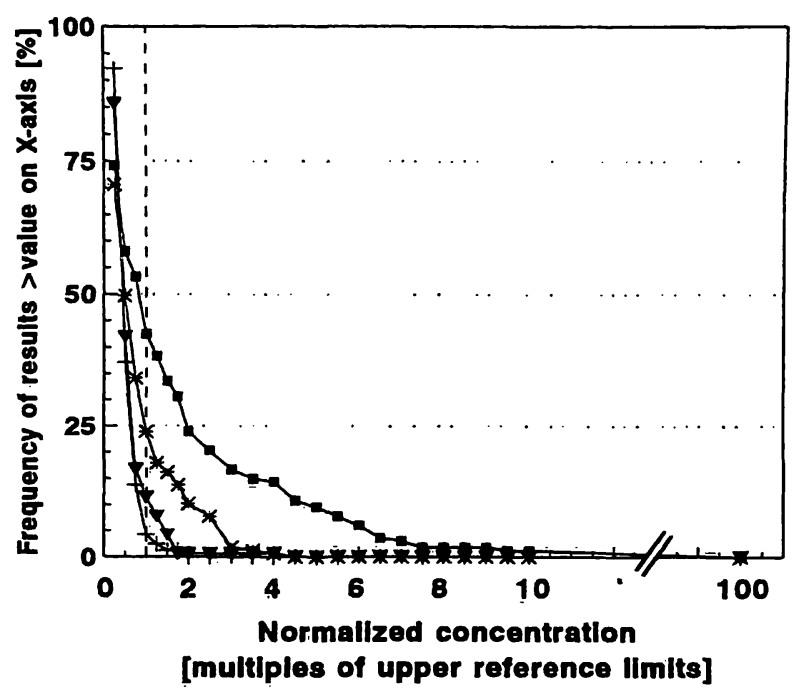

Fig. 4. Frequency $(Y)$ of results $>$ the normalized concentration value on the $\mathrm{X}$-axis $(\mathrm{X})$ for the activity of creatine kinase $(-\nabla-\nabla-)$ and its $\mathrm{MB}$ isoenzyme $(-+-+-)$ and creatine kinase-MB mass concentration $(-*-*-)$ and troponin $\mathrm{T}(-\mathrm{m}-\mathrm{-}-\mathrm{)}$ in patients with unstable angina pectoris (167 samples from 69 patients): Concentrations of the four markers on the $\mathrm{X}$-axis are given as multiples of the upper reference limits. The used upper reference limits were: creatine kinase: men $130 \mathrm{U} / \mathrm{l}$; women $90 \mathrm{U} / \mathrm{l}$, creatine kinaseMB activity: $15 \mathrm{U} / 1$, creatine kinase-MB mass concentration: $5.0 \mu \mathrm{g} / \mathrm{l}$, and troponin $\mathrm{T}: 0.1 \mu \mathrm{g} / \mathrm{l}$. marker under consideration when at least one of the time points gave an elevated result. Sensitivity and specificity were calculated using the upper reference limits for the four markers and the $95 \%$ limits estimated for creatine kinase-MB mass concentration and troponin $\mathrm{T}$ from the patients with unstable angina pectoris (tab. 3).

\section{Discussion}

Reference ranges are usually determined by using serum samples from healthy blood donors or laboratory personnel, a rather young and healthy population compared with the patients the test is meant for. Therefore, we validated the reference range for both the mass concentration of creatine kinase-MB and troponin $\mathrm{T}$ by analysing samples from patients with no acute ischaemic heart disease. For the mass concentration of creatine kinase-MB, $95 \%$ of the results in this patient group were within the reference range $(\ngtr 5.0 \mu \mathrm{g} / \mathrm{l})$. Seven out of 143 results were above the upper reference limit, and all of these were $<7.5 \mu \mathrm{g} / \mathrm{l}$. The results for the mass concentration of creatine kinase-MB obtained from healthy blood do-

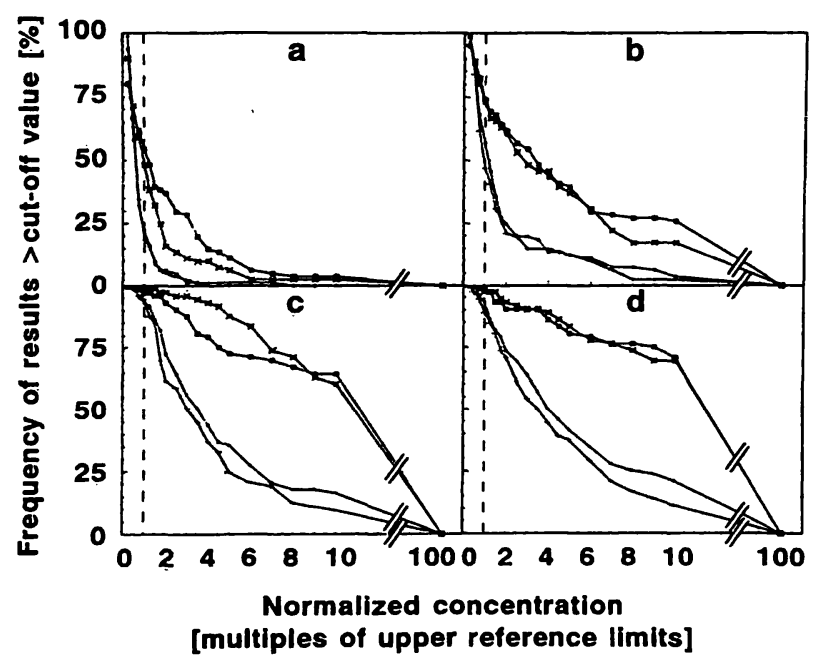

Fig. 5. Frequency $(Y)$ of results $>$ the normalized concentration value on the $\mathrm{X}$-axis $(\mathrm{X})$ for the activity of creatine kinase $(-\nabla-\nabla-)$ and its $M B$ isoenzyme. $(-+-+-)$ and creatine kinase-MB mass concentration $(-*-*-)$ and troponin $\mathrm{T}(-\mathbf{- a}-)$ in patients with acute myocardial infarction. The sample results were divided according to the time delay since onset of chest pain: samples obtained

(a) within 4 hours $(n=81)$,

(b) from $4-8$ hours $(n=81)$,

(c) $8-12$ hours $(n=73)$ and

(d) $12-16$ hours $(\mathrm{n}=72)$

after onset of chest pain. Concentrations of the four markers on the $\mathrm{X}$-axis are given as multiples of the upper reference limits. The used upper reference limits were: creatine kinase: men $130 \mathrm{U} / \mathrm{l}$; women $90 \mathrm{U} / \mathrm{l}$, creatine kinase-MB activity: $15 \mathrm{U} / \mathrm{l}$, creatine kinase-MB mass concentration: $5.0 \mu \mathrm{g} / \mathrm{l}$, and troponin $\mathrm{T}: 0.1 \mu \mathrm{g} / \mathrm{l}$. 
Tab. 2. Number of elevated results in the various patient groups.

\begin{tabular}{|c|c|c|c|c|c|c|c|}
\hline \multicolumn{2}{|l|}{ Patients } & \multicolumn{4}{|c|}{ Creatine kinase } & \multicolumn{2}{|l|}{ Troponin $\mathrm{T}$} \\
\hline \multirow[t]{2}{*}{ Group } & \multirow{2}{*}{$\begin{array}{l}\text { Num- } \\
\text { ber }\end{array}$} & \multirow{2}{*}{ 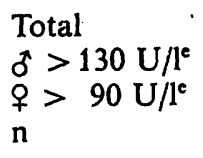 } & \multirow{2}{*}{$\begin{array}{l}\text { MB isoenzyme } \\
\text { activity } \\
>15 \mathrm{U} / 1 \\
\mathrm{n}\end{array}$} & \multicolumn{2}{|c|}{ MB isoenzyme mass } & \multirow[b]{2}{*}{$\underset{\mathrm{n}}{>} 0.1 \mu \mathrm{g} / \mathrm{l}$} & \multirow[b]{2}{*}{$\underset{\mathrm{n}}{>} 0.65 \mu \mathrm{g} / \mathrm{l}$} \\
\hline & & & & $\underset{\mathrm{n}}{>5 \mu \mathrm{g} / 1}$ & $\underset{\mathrm{n}}{>14 \mu \mathrm{g} / \mathrm{l}}$ & & \\
\hline $\begin{array}{l}\text { No acute ischaemic } \\
\text { heart disease }\end{array}$ & 127 & 19 & 14 & $6^{b}$ & $0^{\mathrm{b}}$ & $7^{\mathrm{a}}$ & $0^{b}$ \\
\hline $\begin{array}{l}\text { Unstable } \\
\text { angina pectoris }\end{array}$ & 167 & 19 & $7^{a}$ & $40^{b}$ & $8^{a}$ & $71^{b}$ & $6^{b}$ \\
\hline $\begin{array}{l}\text { Acute myocardial } \\
\text { infarction }\end{array}$ & 409 & 294 & 279 & $341^{b}$ & 279 & $347^{b}$ & $222^{\mathrm{b}}$ \\
\hline $\begin{array}{l}\text { Acute myocardial } \\
\text { infarction } 0-4 \mathrm{~h}^{\mathrm{d}}\end{array}$ & 81 & 18 & 15 & $39^{b}$ & 9 & $44^{b}$ & $4^{b}$ \\
\hline $\begin{array}{l}\text { Acute myocardial } \\
\text { infarction } 4-8 h^{d}\end{array}$ & 81 & 46 & 38 & $59^{a}$ & 40 & $60^{\mathrm{a}}$ & $23^{b}$ \\
\hline $\begin{array}{l}\text { Acute myocardial } \\
\text { infarction } 8-12 \mathrm{~h}^{\mathrm{d}}\end{array}$ & 73 & 68 & 69 & 72 & 70 & 71 & $52^{b}$ \\
\hline $\begin{array}{l}\text { Acute myocardial } \\
\text { infarction } 12-16 \mathrm{~h}^{\mathrm{d}}\end{array}$ & 72 & 67 & 64 & 70 & 66 & 71 & $55^{\mathrm{b}}$ \\
\hline Muscle injury ${ }^{c}$ & 73 & 56 & 60 & 60 & 49 & 58 & 45 \\
\hline Other cardiac disease & 38 & 11 & 8 & 13 & 6 & 15 & 7 \\
\hline
\end{tabular}

$\mathrm{a}: \mathrm{p}<0.05$ and

b. $p<0.01$ : Significant difference of elevated results within patient groups according to Fisher's exact test when compared with total creatine kinase.

c: Muscle injury: patients who had been resuscitated and/or defibrillated.

d: hours since onset of chest pain.

c: upper reference limit for creatine kinase.

Tab. 3. Frequency of patients in each patient group with at least one elevated result in the investigated time period for each marker. Also included are sensitivity and specificity for each marker (patients with muscle injury were excluded from these calculations).

\begin{tabular}{|c|c|c|c|c|c|c|c|}
\hline \multicolumn{2}{|c|}{ Patients } & \multicolumn{4}{|c|}{ Creatine kinase } & \multicolumn{2}{|l|}{ Troponin $\mathrm{T}$} \\
\hline \multirow[t]{2}{*}{ Group } & \multirow{2}{*}{$\begin{array}{l}\text { Num- } \\
\text { ber }\end{array}$} & \multirow{2}{*}{$\begin{array}{l}\text { Total } \\
\delta^{\pi}>130 \mathrm{U} / 1^{\mathrm{a}} \\
\text { o > }>0 \mathrm{U} / 1^{\mathrm{a}} \\
\mathrm{n}\end{array}$} & \multirow{2}{*}{$\begin{array}{l}\text { MB isoenzyme } \\
\text { activity } \\
>15 \mathrm{U} / \mathrm{l} \\
\mathrm{n}\end{array}$} & \multicolumn{2}{|c|}{ MB isoenzyme mass } & & \\
\hline & & & & $\underset{\mathrm{n}}{>} 5 \mu \mathrm{g} / \mathrm{l}$ & $\underset{\mathrm{n}}{>} 14 \mu \mathrm{g} / \mathrm{l}$ & $\underset{\mathrm{n}}{>} 0.1 \mu \mathrm{g} / 1$ & $\begin{array}{l}>0.65 \mu \mathrm{g} / \mathrm{l} \\
\mathrm{n}\end{array}$ \\
\hline
\end{tabular}

Samples obtained within $12 \mathrm{~h}$ after onset of chest pain

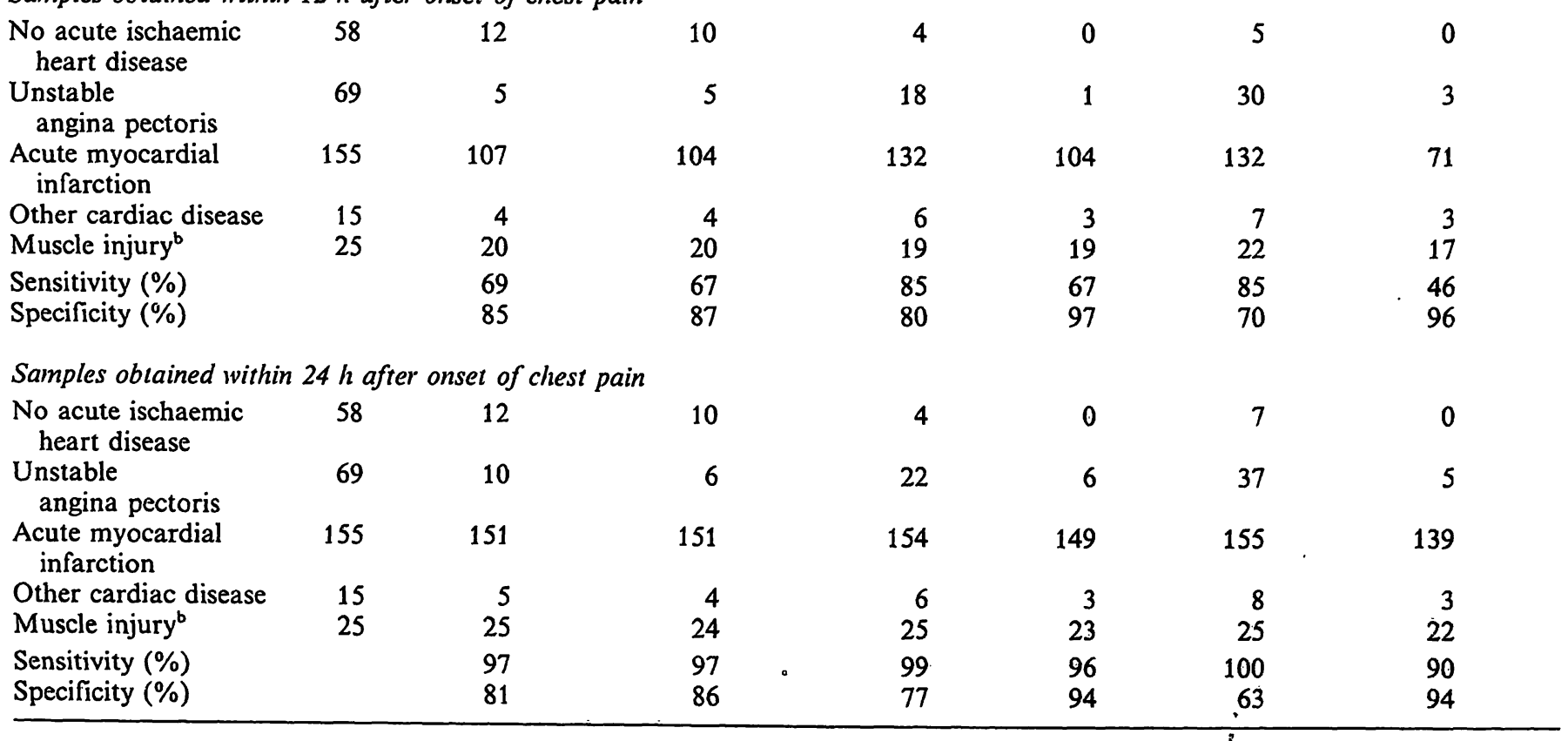

a: upper reference limit for creatine kinase

b: Muscle injury: patients who had been resuscitated and/or defibrillated 


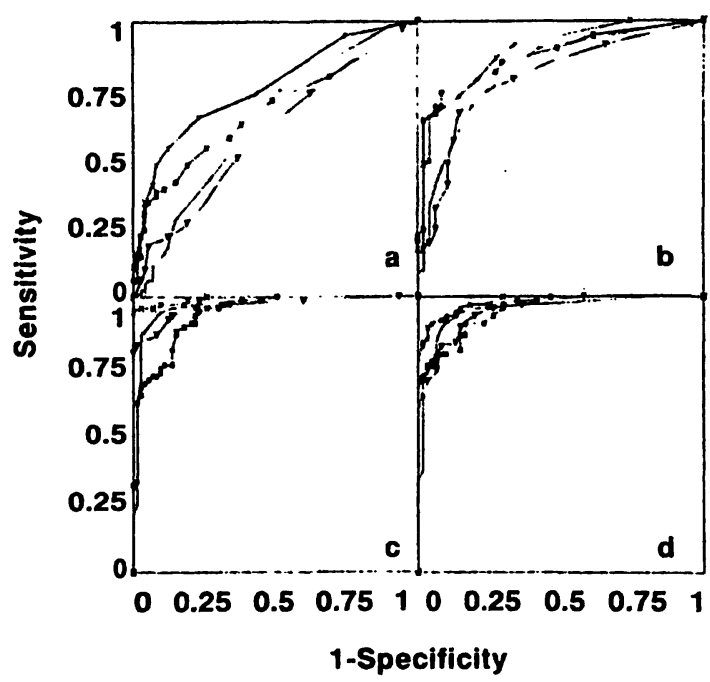

Fig. 6. ROC curves for the activity of creatine kinase $(-\nabla-\nabla-)$ and its MB isoenzyme $(-+-+-)$ and creatine kinase-MB mass concentration ( $-*-*-)$ and troponin $\mathrm{T}(-\square-\nabla-)$ using all samples obtained (a) within 4 hours,

(b) from 4-8 hours,

(c) 8-12 hours and

(d) $12-16$ hours

after onset of chest pain.

\begin{tabular}{|c|c|c|}
\hline \multirow{2}{*}{$\begin{array}{l}\text { Marker } \\
\text { Time since onset of chest pain }\end{array}$} & \multicolumn{2}{|c|}{$\begin{array}{l}\text { Area under the curve } \\
\text { (standard error) }\end{array}$} \\
\hline & $0-4 \mathrm{~h}$ & $4-8 \mathrm{~h}$ \\
\hline $\begin{array}{l}\text { Creatine kinase } \\
\text { Creatine kinase-MB activity } \\
\text { Creatine kinase-MB mass } \\
\text { Troponin T }\end{array}$ & $\begin{array}{l}0.59(0.05) \\
0.63(0.05) \\
0.76(0.04) \\
0.67(0.04)\end{array}$ & $\begin{array}{l}0.76(0.04) \\
0.82(0.04) \\
0.88(0.03) \\
0.86(0.03)\end{array}$ \\
\hline Marker & \multicolumn{2}{|c|}{$\begin{array}{l}\text { Area under the curve } \\
\text { (standard error) }\end{array}$} \\
\hline Time since onset of chest pain & $8-12 h$ & $12-16 \mathrm{~h}$ \\
\hline $\begin{array}{l}\text { Creatine kinase } \\
\text { Creatine kinase-MB activity } \\
\text { Creatine kinase-MB mass } \\
\text { Troponin T }\end{array}$ & $\begin{array}{l}0.97(0.02) \\
0.97(0.02) \\
0.99(0.01) \\
0.94(0.02)\end{array}$ & $\begin{array}{l}0.95(0.02) \\
0.96(0.02) \\
0.98(0.01) \\
0.94(0.02)\end{array}$ \\
\hline
\end{tabular}

nors agree with those obtained from patients with no acute ischaemic heart disease. They also agreed with the reference ranges found in other studies $(6,20,24)$. For the concentration of troponin $\mathrm{T}, 95 \%$ of the results were below the upper reference limit of 0.1 $\mu \mathrm{g} / \mathrm{l}$. Of the results ( 7 out of 141 ) above this limit, only 1 exceeded $0.20 \mu \mathrm{g} / \mathrm{l}$, the upper reference limit suggested by the manufacturer. The results for troponin $\mathrm{T}$ in healthy blood donors also agree with those obtained from patients with no acute ischaemic heart disease. The upper reference limit found in this study for troponin $\mathrm{T}$ is also in line with that $(0.06 \mu \mathrm{g} / \mathrm{l})$ found by Gerhardt et al. (25), but is considerably lower than that $(0.5 \mu \mathrm{g} / \mathrm{l})$ reported by Mair et al. (17). The difference can be explained by the more sensitive assay used in this study and by Gerhardt et al.
In patients with no acute ischaemic heart disease, the frequency of elevated results for the activity of creatine kinase $(n=19)$ and creatine kinase-MB $(n=14)$ was slightly higher than for the mass concentration of creatine kinase-MB and troponin T. Most of the sera $(n=11)$, in which the activity of creatine kinase exceeded the upper reference limit, displayed a normal value for the ratio of the activity of creatine kinase$\mathrm{MB}$ to the activity of total creatine kinase (a ratio $<6 \%$ excludes myocardial infarction). Four elevated results were explained by the presence of a macromolecular creatine kinase. The remaining 4 samples with an elevated activity of creatine kinase were haemolytic; since haemolysis is known to interfere in these assays by the liberation of adenylate kinase from erythrocytes (9), all elevated results for the activity of creatine kinase are considered falsely elevated. The elevated results for the activity of creatine kinase-MB also were considered falsely elevated, since the sera in question contained macromolecular creatine kinase (7 samples) or were subject to haemolysis (7 samples). The assay for the mass concentration of creatine kinase-MB and troponin $\mathrm{T}$ therefore led to a lower frequency of falsely elevated results.

The ratio of the activity of creatine kinase-MB to the total activity of creatine kinase is usually advocated for the evaluation of myocardial damage in patients with an elevated total creatine kinase activity. However, this ratio is worthless as a single indicator, because at low concentrations of total creatine kinase it often gives rise to values $>6 \%$ (a ratio $<6 \%$ excludes myocardial infarction). This calculated indicator was therefore not considered in this study.

The frequency of elevated results for troponin $T$ and the mass concentration of creatine kinase-MB in patients with unstable angina pectoris was significantly higher than the frequency for the activities of both creatine kinase and creatine kinase-MB. Almost 25\% of the results for the mass concentration of creatine kinase-MB were above the upper reference limit. The upper limit (95th percentile) for the mass concentration of creatine kinase-MB found in samples from patients with unstable angina pectoris was estimated at $14 \mu \mathrm{g} / \mathrm{l}$, which was considerably higher than the upper reference limit. For troponin $T$, about $40 \%$ of the results were above the upper reference limit, and almost $25 \%$ were $>0.2 \mu \mathrm{g} / \mathrm{l}$, the upper reference limit suggested by the manufacturer. The upper limit (95th percentile) for troponin $T$ found in samples from patients with unstable angina pectoris was estimated at $0.65 \mu \mathrm{g} / \mathrm{l}$, which, like the mass concentration of creatine kinase-MB, was considerably higher than the upper reference limit. The occurrence of these slight elevations for both the mass concentration of creatine 
kinase-MB $(26,27)$ and troponin $\mathrm{T}(28)$ in patients with unstable angina pectoris was described recently. These slight elevations were correlated with a significantly higher risk for the development of acute myocardial infarction and requiring revascularization. Therefore, it is reasonable to suppose that minor myocardial damage, which remained undetectable with the less sensitive methods for creatine kinase and creatine kinase-MB used so far, can release small amounts of these proteins. The meaning of these slight elevations of both the mass concentration of creatine kinase- $\mathrm{MB}$ and troponin $\mathrm{T}$ (using these sensitive new assays) in patients without myocardial infarction according to the WHO criteria (using the insensitive methods for measuring enzyme activity) however, remains to be established. The frequency of elevated results for both creatine kinase and creatine kinase$\mathrm{MB}$ activity in patients with unstable angina pectoris did not differ from that of healthy blood donors.

The frequency of elevated results for the patients with acute myocardial infarction was evaluated in different time-windows, because the release of the markers is time-dependent. Within 4 hours after the onset of chest pain, suggestive of acute myocardial infarction, $<20 \%$ of the patients displayed elevated values for the activities of creatine kinase and creatine kinaseMB. In about $50 \%$ of the patients, elevated results were encountered for the mass concentrations of creatine kinase-MB and troponin $\mathrm{T}$. No significant difference was seen between the frequencies of elevated results for the mass concentrations of creatine kinase$\mathrm{MB}$ and troponin T. Evaluation of the next 4 hour period revealed at a higher percentage the same kind of differences. Evaluation at more than 8 hours after onset of chest pain showed no significant differences between the frequency of elevated results for the activities of creatine kinase and creatine kinase-MB and the mass concentrations of creatine kinase-MB and troponin $T$. Using the upper reference limits estimated in samples from healthy blood donors and verified with samples from patients with no acute ischaemic heart disease, the sensitivity for both the mass concentration of creatine kinase-MB and troponin $\mathrm{T}$ was considerably better in the first 12 hours after onset of chest pain than the sensitivity for the activity of creatine kinase and creatine kinase-MB (tab. 3). The specificity, however, was worse. This was ascribed to the rather high number of patients with a final diagnosis of unstable angina pectoris, who had elevated results for the mass concentration of creatine kinase$\mathrm{MB}$ and/or troponin T. These patients with slight elevations of creatine kinase-MB mass concentration or troponin $\mathrm{T}$ are false-positive according to the WHO criteria, but they possibly constitute a subgroup of patients with myocardial infarction with an increased risk of major cardiovascular disease as a consequence of minor myocardial damage. Although the best marker for early (within 12 hours after onset of chest pain) diagnosis of acute myocardial infarction (according to the WHO criteria) was the mass concentration of creatine kinase-MB according to the ROC curve analysis, such a conclusion does not take into account the importance of detecting minor myocardial damage in patients not yet fulfilling the WHO criteria for myocardial infarction. Such patients probably carry an increased risk for major cardiovascular disease, so that their detection might lead to a more aggressive therapy (i. e. coronary angiography followed by subsequent revascularization), which might improve their prognosis.

By using the higher limits for the mass concentration of creatine kinase-MB and troponin $\mathrm{T}$ (estimated in patients with unstable pectoris), the specificity was improved, with an accompanying loss of sensitivity. Using these higher limits, the mass concentration of creatine kinase-MB again was the best marker for the early diagnosis of acute myocardial infarction, but such a conclusion again does not take into account the importance of detecting minor myocardial damage.

In patients with myocardial infarction, Katus et al. (15) presented data suggesting that the release of troponin $T$ precedes that of creatine kinase and creatine kinase-MB determined by activity measurement. Our results support their findings, but when we used a sensitive assay for the determination of the mass concentration of creatine kinase-MB, we found no significant differences between the times of release of troponin $\mathrm{T}$ and creatine kinase-MB. Our observation that the mass concentration of creatine kinase-MB rose before the activity of creatine kinase and creatine kinase-MB has also been reported by others (6). Therefore, we do not agree with Katus et al. that the release of troponin $T$ from the damaged myocardium precedes that of creatine kinase-MB. Their observation was merely a consequence of the insensitive assays for the measurement of creatine kinase and creatine kinase-MB activity.

In conclusion, we have shown (1) that troponin $\mathrm{T}$ and the mass concentration of creatine kinase-MB display the same release pattern after myocardial infarction, (2) that for the early diagnosis of myocardial infarction according to the WHO criteria, the measurement of the mass concentration of creatine kinase-MB performs better (according to ROC curve analysis) in comparison with troponin $\mathrm{T}$ 'and the activity measurements of creatine kinase and its MB-isoenzyme, 
and (3) that in samples from patients with unstable angina pectoris the mass concentrations of creatine kinase-MB and troponin $\mathrm{T}$ are elevated in a considerable number of the patients, which can be used to identify a subgroup of patients without myocardial infarction, who might benefit from a more aggressive treatment. The measurement of the mass concentration of creatine kinase-MB is preferred for rapid and early diagnosis of myocardial infarction, especially when one considers that the measurement of troponin $\mathrm{T}$ takes at least $90 \mathrm{~min}$, whereas the mass concentra-

\section{References}

1. Rude, R. E., Poole, W. K., Muller, J. E., Turi, Z., Rutherford, J., Parker, C., Roberts, R., Raabe, D. S., Gold, H. K., Stone, P. H., Willerson, J. T., Braunwald, E. \& the MILIS study group (1983) Electrocardiographic and clinical critcria for recognition of acute myocardial infarction based on analysis of 3697 patients. Am. J. Cardiol. 52, 936-942.

2. Turi, Z. G., Rutherford, J. D., Roberts, R., Muller, J. E., Jaffe, A. S., Rude, R. E., Parker, C., Raabe, D. S., Stone, P. H., Hartwell, T. D., Lewis, S. E., Parkey, R. W., Gold, H. K., Robertson, T. L., Sobel, B. E., Willerson, J. T., Braunwald, E. \& cooperating investigators from the MILIS study group (1985) Electrocardiographic, enzymatic and scintigraphic criteria of acute myocardial infarction as determined from study of 726 patients (a MILIS study). Am. J. Cardiol. 55, 1463-1468.

3. White, R. D., Grande, P., Califf, L., Palmeri, S. T., Califf, R. M. \& Wagner, G. S. (1985) Diagnostic and prognostic significance of minimally elevated creatine kinase-MB in suspected acute myocardial infarction. Am. J. Cardiol. 55, $1478-1484$.

4. Delanghe, J. R., de Mol, A. M., de Buyzere, M. L., de Scheerder, I. K. \& Wieme, R. J. (1990) Mass concentration and activity concentration of creatine kinase isoenzyme $\mathrm{MB}$ compared in serum after acute myocardial infarction. Clin. Chem. 36, 149-153.

5. Collinson, P. O., Rosalki, S. B., Kuwana, T., Garratt, H. M., Ramhamadamy, E. M., Baird, I. M. \& Greenwood, T. W. (1992) Early diagnosis of acute myocardial infarction by CK-MB mass measurements. Ann. Clin. Biochem. 29, $43-47$.

6. Mair, J., Artner=Dworzak, E., Dienstl, A., Lechleitner, P., Morass, B., Smidt, J., Wagner, I., Wettach, C. \& Puschendorf, B. (1991) Early detection of acute myocardial infarction by measurement of mass concentration of creatine kinase-MB. Am. J. Cardiol. 68, 1545-1550.

7. Wolfson, D., Lindberg, E., Su, L., Farber, S. J. \& Dubin, S. B. (1991) Three rapid immunoassays for the determination of creatine kinase MB: An analytical, clinical and interpretive evaluation. Am. Heart. J. 122, 958-964.

8. Gibler, W. B., Lewis, L. M., Erb, R. E., Makens, P. K., Kaplan, B. C., Vaughn, R. H., Biagini, A. V., Blanton, J. D. \& Campbell, W. B. (1990) Early detection of acute myocardial infarction in patients presenting with chest pain and nondiagnostic ECGs: Serial CK-MB sampling in the emergency department. Ann. Emerg. Med. 19, 1359-1366.

9. Moss, D. W., Henderson, A. R. \& Kachmar, J. F. (1986) Enzymes. In: Textbook of Clinical Chemistry (Tietz, N. W., ed.) Philadelphia; W. B. Saunders Company, pp. 678-691.

10. Hørder, M., Elser, R. C., Gerhardt, W., Mathieu, M. \& Sampson, E. J. (1991) Approved recommendation on IFCC methods for the measurement of catalytic concentrations of enzymes, part 7. IFCC Method for Creatine Kinase. Eur. J. Clin. Chem. Clin. Biochem. 29, 435-456. tion of creatine kinase-MB can be measured in less than $10 \mathrm{~min}(29)$.

\section{Acknowledgement}

The reagents for the immunological determination of troponin $T$ used throughout these investigations were a gift from Boehringer Mannheim. The reagents for the immunological determination of the mass concentration of creatine kinase-MB were a gift from Abbott. Finally, we thank Dr. Jan Tijssen and Mark Koelemay from the Department of Clinical Epidemiology and Biostatistics of the Academisch Medisch Centrum in Amsterdam for their statistical support.

11. Griffiths, P. D. (1986) CK-MB a valuable test? (Review) Ann. Clin. Biochem. 23, 238-242.

12. Stein, W., Bohner, J. \& Bahlinger, M. (1985) Analytical patterns and biochemical properties of macro creatine kinase type 2. Clin. Chem. 31, 1952-1958.

13. Rogalsky, V. Y., Koven, I. H., Miller, D. R. \& Pollard, A. (1985) Macro creatine kinase type 2 in human colonic tissues. Clin. Biochem. 18, 338-341.

14. Katus, H. A., Remppis, A., Looser, S., Hallermeier, K., Scheffold, T. \& Kübler, W. (1989) Enzyme linked immuno assay of cardiac Troponin $T$ for the detection of acute myocardial infarction in patients. J. Mol. Cell. Cardiol. 21, 1349-1353.

15. Katus, H. A., Remppis, A., Neumann, F. J., Scheffold, T., Diederich, K. W., Vinar, G., Noe, A., Matern, G. \& Kuebler, W. (1991) Diagnostic efficiency of Troponin T measurements in acute myocardial infarction. Circulation 83, 902-912.

16. Katus, H. A., Looser, S., Hallermayer, K., Remppis, A., Scheffold, T., Borgya, A., Essig, U. \& Geusz, U. (1992) Development and in vitro characterization of a new immunoassay of cardiac Troponin T. Clin. Chem. 38, 386393.

17. Mair, J., Artner-Dworzak, E., Lechleitner, P., Smidt, J., Wagner, I., Dienstl, F. \& Puschendorf, B. (1991) Cardiac Troponin $\mathrm{T}$ in diagnosis of acute myocardial infarction. Clin. Chem. 37, 845-852.

18. Gerhardt, W., Katus, H. A., Ravkilde, J., Hamm, C., Jørgensen, P. J., Peheim, E., Ljungdahl, L. \& Löfdahl, P. (1991) S-Troponin T in suspected ischemic myocardial injury compared with mass and catalytic concentrations of s-creatine kinase isoenzyme MB. Clin. Chem. 37, 14051411.

19. World Health Organization (1981) WHO criteria for the diagnosis of acute myocardial infarction. Proposal for the multinational monitoring of trends and determinants in cardiovascular disease. Geneva: Cardiovascular Disease Unit of the WHO.

20. Hanley, J. A. \& McNeil, B. J. (1982) The meaning and use of the area under a Receiver Operating Characteristic (ROC) curve. Radiology 143, 29-36.

21. Hanley, J. A. \& McNeil, B. J. (1983) A method of comparing the areas under Receiver Operating Characteristic curves derived from the same cases. Radiology 148, 839843.

22. Brandt, D. R., Gates, R. C., Eng, K. K., Forsythe, C. M., Korom, G. K., Nitro, A. S., Koffler, P. A. \& Ogunro, E. A. (1990) Quantifying the MB isoenzyme of creatine kinase with the Abbott "IMx" immunoassay analyzer. Clin. Chem. $36,375-378$.

23. Solberg, H. E. (1983) The theory of reference values, part 5. Statistical treatment of collected reference values. Determination of reference limits. J. Clin. Chem. Clin. Biochem. $21,749-760$. 
24. Chapelle, J. P. \& Allaf, M. E. (1990) Autornated quantification of creatine kinase $\mathrm{MB}$ isoenzyme in serum by radial partition immunoassay with use of the Stratus analyzer. Clin. Chem. 36, 99-101.

25. Gerhardt, W., Katus, H. A., Ravkilde, J. \& Hamm, C. W. (1992) S-Troponin T as a marker of ischemic myocardial injury (letter). Clin. Chem. 38, 1194-1195.

26. Markenvard, J., Dellborg, M., Jagenburg, R. \& Swedberg, K. (1992) The predictive value of CKMB mass concentration in unstable angina pectoris: preliminary report. J. Intern. Med. 231, 433-436.
27. Ravkilde, J., Hañsen, A. B., Hørder, M., Jørgensen, P. J. \& Thygesen, K. (1992) Risk stratification in suspected acute myocardial infarction based on a sensitive immunoassay for serum creatine kinase isoenzyme MB. Cardiology 80 , $143-151$.

28. Hamm, C. W., Ravkilde, J., Gerhardt, W., Jørgensen, P., Peheim, E., Ljungdahl, L., Goldmann, B. \& Katus, H. A. (1992) The prognostic value of serum Troponin T in unstable angina. N. Engl. J. Med. 327, 146-150.

29. Apple, F. S., Preese, L. M., Riley, L., Gerken, K. L. \& van Lente, F. (1990) Financial impact of a rapid CK-MBspecific immunoassay on the diagnosis of myocardial infarction. Arch. Pathol. Lab. Med. 114, 1017-1020.

A. J. Bakker

Dept. of Clinical Chemistry

Klinisch Chemisch Laboratorium

P. O. Box 850

NL-8901 BR Leeuwarden

The Netherlands 